\title{
Dynamic Behavior and Serviceability Analysis of a New Type of U-Shaped Steel-Concrete Composite Floor Slab
}

\author{
Yaqin Lu $\mathbb{D},{ }^{1}$ Hongkun Shang, ${ }^{2}$ Zhengnong Li $\left(\mathbb{D},{ }^{3}\right.$ Kejian $\mathrm{Ma},{ }^{1}$ and Lan Jiang ${ }^{3}$ \\ ${ }^{1}$ Space Structures Research Center, Guizhou University, Guiyang, China \\ ${ }^{2}$ College of Civil Engineering, Qingdao University of Technology, Qingdao, China \\ ${ }^{3}$ Civil Engineering College, Hunan University, Changsha, China \\ Correspondence should be addressed to Yaqin Lu; luya_2000@163.com
}

Received 29 November 2019; Accepted 24 February 2020; Published 30 June 2020

Academic Editor: Rosario Montuori

Copyright () 2020 Yaqin Lu et al. This is an open access article distributed under the Creative Commons Attribution License, which permits unrestricted use, distribution, and reproduction in any medium, provided the original work is properly cited.

\begin{abstract}
A new type of U-shaped steel-concrete composite floor is analyzed in detail. The experimental test and finite element analysis of the floor are conducted to study the natural frequency and serviceability characteristics of the new composite floor structure. The natural frequency of the floor is measured under the environmental random vibration stimulating method, and the peak acceleration of the floor is measured under pedestrian-induced load. The experimental test results show that the U-shaped steelconcrete composite floor has better antiseismic behaviors and meet the specified serviceability requirements. The finite element analysis results indicate the constraints have a great impact on the calculation results. The experimental tests and FEM results of the floor are compared based on the modal assurance criterion, and the results are in good agreement. The experimental test acceleration curves demonstrate that the peak values meet the requirements of Chinese specification.
\end{abstract}

\section{Introduction}

The floor structure system has a great influence on the buildings. The conventional floor structure can meet the interior space requirement of general buildings, e.g., concrete floor structure $[1,2]$, prestressed concrete floor structure [3], steel-concrete composite floor structure [4-6], and space grid-concrete slab composite structure [7]. The conventional floor structure can be used for long-span structure through reasonable design and construction. However, long-span buildings require a larger interior space. The section height of beam increases with the increase of the span of the building, thus increasing the total height of conventional floor structures [8-10]. Therefore, it is necessary to invent an innovative floor structure which meets the larger interior space requirement and suits for long-span industrial and public buildings.

To meet the requirement, the U-shaped steel-concrete composite floor system has been invented recently in China to provide a floor system with a desirable long-span capacity and minimum constructional height $[11,12]$. The floor structure system is composed of top ribs, bottom ribs, shear keys, a thin plate of the surface layer, and a U-shaped steel plate around the bottom ribs (Figure 1). Electrical and plumbing conduits can pass through the empty space between the top and bottom ribs, increasing the interior net height or reducing the floor height. The cracking and tensile problems of concrete beam bending large moment can be solved by adding U-shape steel around the bottom ribs, which enhances the span capacity of the U-shaped steelconcrete composite floor structure. The U-shaped steelconcrete composite floor system is suitable for long-span industrial and public buildings and has been applied in many projects $[11,12]$ (Figure 2). For example, the effective span of the Heilongjiang University of Chinese Medicine Amusement and Sports Center is $39 \mathrm{~m}$. The application of the aforementioned floor has the following advantages compared with the conventional floor: lower construction cost, less material consumption, lower floor height, rapid construction speed, and many others $[13,14]$. Therefore, it can meet the large interior space requirement of industrial and public buildings. 


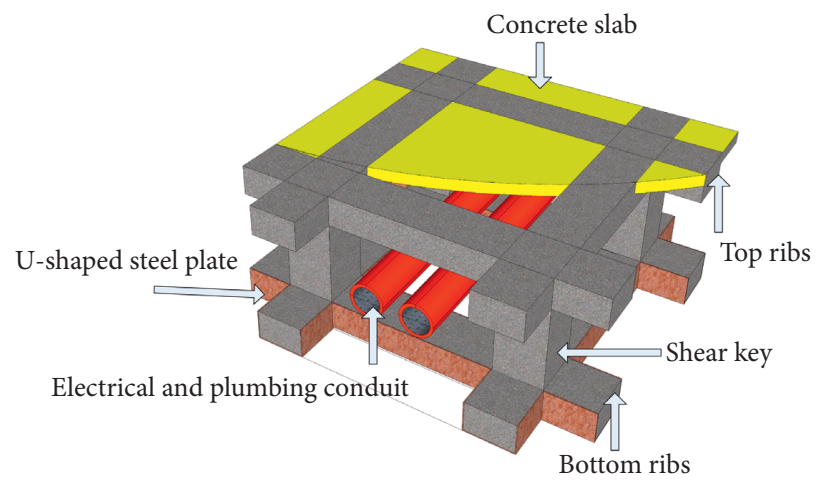

FIgure 1: Components of the composite floor.
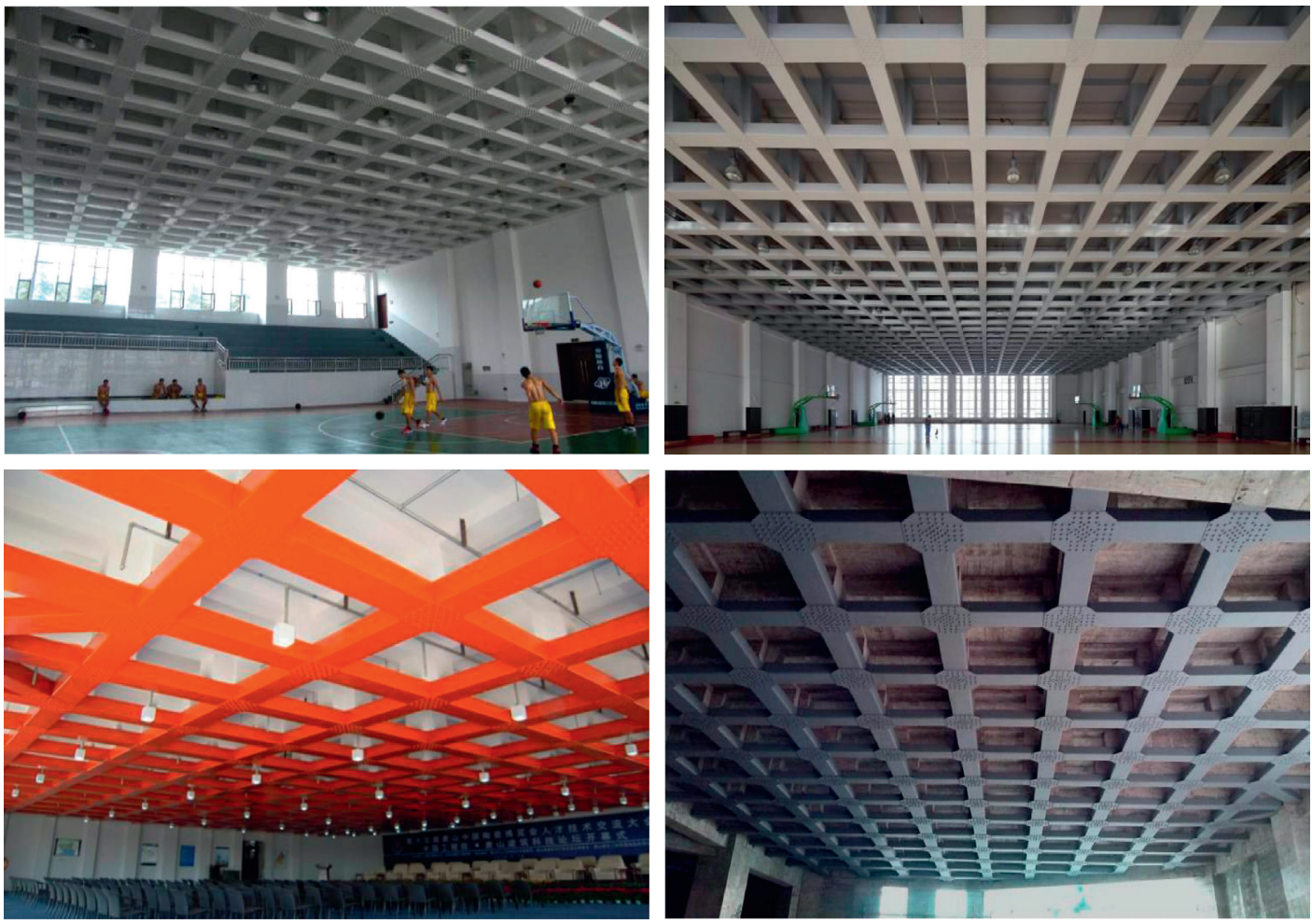

Figure 2: Engineering examples.

Long-span floor structure has the characteristics of large span, small mass, large stiffness, large damping ratio, and small natural frequency. Human activities have a great impact on the long-span buildings [15]. Human discomfort may be caused by excessive vibrations under human-induced loads, which limits the application of the U-shaped steel-concrete floor system. Therefore, it is very important to carry out the dynamic behavior and serviceability of the aforementioned floor research program.

A great deal of research on human-induced vibration has been conducted in [16-23], and many countries have published the codes and guidelines for the human-induced vibration of structures. However, they are suitable for the conventional floor structures. As the U-shaped steelconcrete composite floor structure is an innovative floor structure in China, its mass, stiffness, damping, and boundary conditions are different from those of the conventional floor structures. As a new form of spatial structure, there are few research results available for the vibration mechanism of the U-shaped steel-concrete composite floor.

The purpose of this paper is to analyze the dynamic behavior and serviceability of the U-shape steel-concrete composite floor.

To achieve this goal, the following work has been done:

(1) The experimental test of the vertical vibration model of U-shaped steel-concrete composite floor slab was performed by environmental excitation. The pedestrian-induced acceleration test of the floor was carried out under eight kinds of test conditions. 
(2) The finite element analysis of the floor was established to study its vibration behavior and serviceability.

(3) The experimental test results and FEM modal results of the structure were compared based on the modal assurance criterion, including the natural frequency and the peak acceleration under pedestrian-induced loads.

\section{Materials and Methods}

2.1. Criteria of Floor Serviceability. The vertical natural frequency of residences and apartments, office buildings and hotels, and long-span public buildings should, respectively, not be less than $5 \mathrm{~Hz}, 4 \mathrm{~Hz}$, and $3 \mathrm{~Hz}$ according to the Concrete Structures Design Specification [24].

The vertical natural frequency of the floor structure should not be less than $3 \mathrm{~Hz}$ according to the Technical Regulations on Concrete Structures in High-Rise Buildings [25]; the peak value of the vibration acceleration is shown in Table 1. The limit of peak acceleration can be chosen by linear interpolation when the vertical natural frequency is between 2 and $4 \mathrm{~Hz}$.

The natural frequency of the floor structure should be between $4 \mathrm{~Hz}$ and $8 \mathrm{~Hz}$ according to Code of Design and Construction of Composite Building [26]; the vertical peak acceleration of residences and office buildings, shopping mall and interior gallery should, respectively, not be more than $0.005 \mathrm{~g}$ and $0.015 \mathrm{~g}$, where $\mathrm{g}$ is the acceleration of gravity.

ATC40 shows the serviceability of the floor based on damping ratio and peak acceleration listed in Table 2. $\beta$ is damping ratio, $\alpha_{0}$ is maximum peak acceleration, and $g$ is the acceleration of gravity.

2.2. Project Description. As shown in Figure 3, the floor connects with the other rooms. The yield strength of the $\mathrm{U}$-shaped steel is $310 \mathrm{~N} / \mathrm{mm}^{2}$, and the compressive strength of concrete is $19.1 \mathrm{~N} / \mathrm{mm}^{2}$. The plane span of the floor is $25.2 \mathrm{~m}$, and the total height of the floor is $1.2 \mathrm{~m}$. Figure 4 schematically shows the U-shaped steel-concrete composite floor.

2.3. Field Measurements of the Floor Slab. The experimental test on the vertical vibration and peak acceleration of the U-shaped steel-concrete composite floor were performed. The natural frequency, damping ratio, modal shape, and vertical peak acceleration were obtained. All of the test data were collected by the DHC DH5910 data collector system, which had eight channels and seven TAISETE TST126V accelerometer sensors and a laptop.

2.3.1. Modal Test. The test methods include the peak pickup method and the power spectrum principle. The maximum value of the frequency-response function (FRF) is near the natural frequency [27]. In this method, the FRF is replaced by the power spectrum of the response. If a mode corresponds to a peak value of the power spectrum, this value can be used to obtain the natural frequency.

The degree of freedom of the structure is $N$, where $N$ is three times of the number of floors, the external load is excited on point $p$, and the FRF of point $l$ can be expressed as [27]:

$$
H_{\mathrm{lp}}(\varpi)=\sum_{r=1}^{N} \frac{1}{K_{\mathrm{er}}}\left[\frac{1-\varpi_{r}^{2}}{\left(1-\varpi_{r}^{2}\right)^{2}+g_{r}^{2}}+j \frac{-g_{r}}{\left(1-\varpi_{r}^{2}\right)^{2}+g_{r}^{2}}\right],
$$

where $\Phi_{r}=\omega / \omega_{r}$ is the frequency ratio, $\omega_{r}$ is the natural frequency of the structure, $K_{\mathrm{er}}=K_{r} / \phi_{\mathrm{lr}} \phi_{\mathrm{pr}}$ is the equivalent stiffness of the $r$ th order, $K_{r}$ is the modal stiffness of the $r$ th order, and $\phi_{\mathrm{lr}}$ and $\phi_{\mathrm{pr}}$ are the modal vectors of the $r$ th order at points $l$ and $p$, respectively.

The self-power spectrum and cross-power spectrum can be obtained from the test data as follows:

$$
G_{x x}(\omega)-|H(\omega)|^{2} G_{y y}(\omega)=0,
$$

where $G_{x x}$ and $G_{y y}$ are unilateral self-power spectral density functions, respectively. The extreme point of the self-power spectrum can be obtained by deriving $\omega$.

In a system that can be input, output, and tested, the natural frequency appears in the position of the frequency response function, and the corresponding peak value also appears in the amplitude-frequency diagram. The environmental random vibration stimulating method is adopted in this test, which can only test the response signal of the system and calculate the frequency of the floor according to the above formula.

In the experimental test, seven acceleration sensors are employed to measure the vibration responses of the longspan floor. According to the vibration characteristics of the floor obtained by FEM and the field situation, the intersection points of the top ribs and bottom ribs are selected as the measuring points. There are a total of 38 measuring points, and the distribution is shown in Figure 5. Measuring point 8 is the modal reference point, which is a fixed point during the whole testing process.

The test had been done under environmental random vibration stimulating method, and any activity in the U-shape steel-concrete composite floor was forbidden. The natural frequency, modal shape, and damping ratio can be obtained from the measured responses of the structure. The main structure of the MNG project had been completed before testing. Firstly, the data collecting system collected and analyzed the vibration responses of the floor. Then, the frequency response function data are analyzed using the DHC modal analysis system. Finally, the modal parameters were obtained by the modal parameter identification method.

The precise locations for all measuring points were acquired with the measuring instrument. Measuring points were marked, polished, and numbered. The sampling frequency was $100 \mathrm{~Hz}$, and the analyzing frequency was $39.06 \mathrm{~Hz}$.

The test equipment was calibrated to meet the accuracy requirements; the position of the reference point was fixed. The test data for all measuring points are acquired sequentially. 
TABLE 1: Vertical vibration acceleration limit of the floor.

\begin{tabular}{lcc}
\hline \multirow{2}{*}{ Activity environment } & \multicolumn{2}{c}{ Peak acceleration limit $\left(\mathrm{m} / \mathrm{s}^{2}\right)$} \\
& Vertical natural frequency not more than $2 \mathrm{~Hz}$ & Vertical natural frequency not less than $4 \mathrm{~Hz}$ \\
\hline Residence, office & 0.07 & 0.05 \\
Shopping mall, interior gallery & 0.22 & 0.15 \\
\hline
\end{tabular}

TABLe 2: Vertical vibration acceleration limit of floor in ATC.

\begin{tabular}{lcc}
\hline Activity environment & $\beta$ & $\alpha_{0}(g)$ \\
\hline Residence, office & $0.02 \sim 0.05$ & 0.005 \\
Shopping mall & 0.02 & 0.015 \\
Interior gallery & 0.01 & 0.015 \\
\hline
\end{tabular}

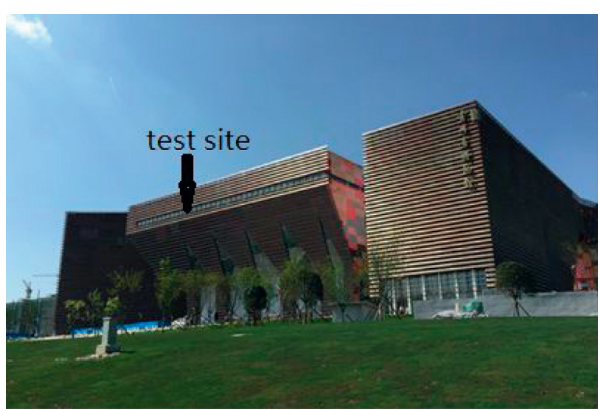

(a)

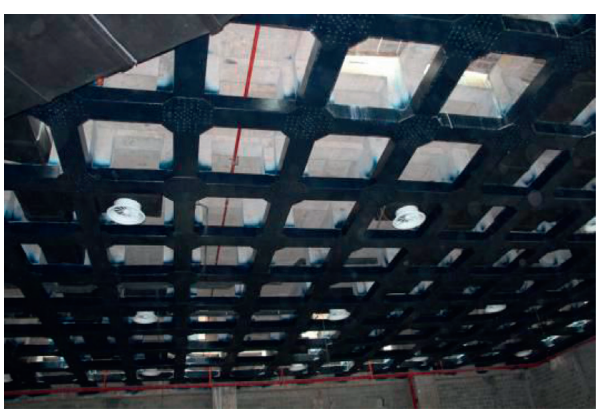

(b)

FIgURE 3: Long-span composite floor: (a) exterior view; (b) interior view.

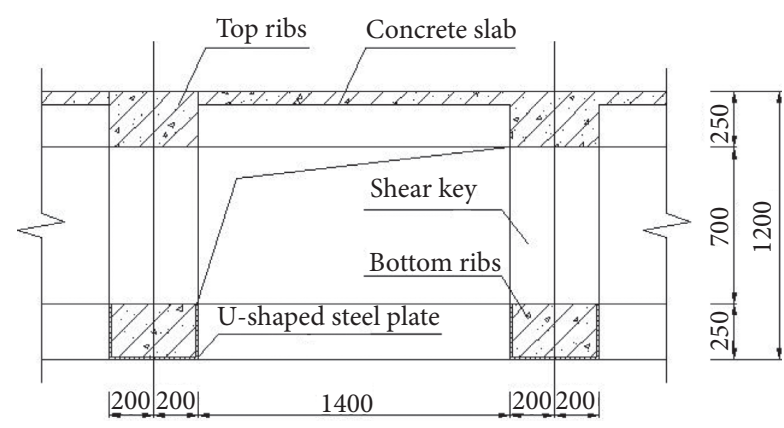

Figure 4: Profile of the composite floor.

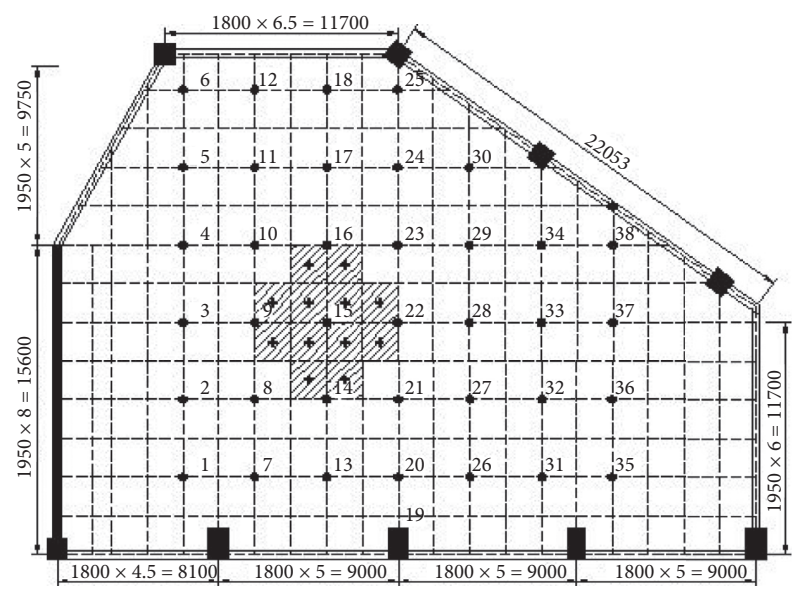

Figure 5: Measuring point layout of the composite floor.
2.3.2. Pedestrian-Induced Acceleration. A time-history analysis method was applied to analyze the vertical vibration accelerations of the floor. The peak acceleration excited by pedestrian-induced vibration can be expressed as

$$
\begin{aligned}
& \alpha_{p}=\frac{F_{p}}{\beta \omega} g, \\
& F_{p}=p_{0} e^{-0.35 f_{n}},
\end{aligned}
$$

where $\alpha_{p}$ is the vibration acceleration of the floor $\left(\mathrm{m} / \mathrm{s}^{2}\right), F_{p}$ is the pedestrian-induced force with the frequency near the natural frequency $(\mathrm{kN}), \beta$ is the damping ratio of the floor, is the impedance of the floor, $g$ is acceleration of gravity, $p_{0}$ is the force by pedestrian-induced vibration, and $f_{n}$ is the vertical natural frequency of the floor.

While measuring the peak acceleration of the floor, eight test conditions were considered: solo experimenter stepping; solo experimenter jumping; solo experimenter walking along a designated route; 10 experimenters in a line walking along a designated route; 10 experimenters in a row walking along a designated route; 12 experimenters stepping; 12 experimenters jumping; and 12 experimenters walking in a designated area. The weight of an experimenter is $70 \mathrm{~kg}$.

Twelve experimenters were selected and measured on height, weight, and normal step frequency. For the jumping tests, the test conditions were divided into three frequencies: $1.7 \mathrm{~Hz}, 2.1 \mathrm{~Hz}$, and $2.4 \mathrm{~Hz}$. The acceleration measuring points are located near the centroid of the first modal as shown in Figure 3; the experimenters stood precisely at the 
center point of each grid. The experimenters jumped according to the frequency of the sound. When the jumping frequency agreed well with the sound frequency, the data collecting system began to work. The excitation time of every measurement lasted $40 \mathrm{~s}$.

\subsection{Finite Element Analyses}

2.4.1. Modal Test. The beam element is used to model the columns, top ribs, bottom ribs, shear keys, and U-shaped steel. The shell element is used to model the thin plate, frame beams, and shear walls. Under the action of dynamic load, the elastic modulus of the concrete increased by $20 \%$. Poisson's ratio is 0.2 , and the damping ratio is 0.02 . The FEM model is shown in Figure 6. Based on the stiffness of the top/ bottom layer columns, the height of the top/bottom layer columns is half the height of the story. The linear displacement constraint in three directions is at the end of the columns. Petyt and Mirza [28] prove that flexural stiffness plays an important role in the natural frequency of the floor. The boundary conditions have a significant impact on the natural frequency and dynamic responses [29]. The test floor is part of the main structure and is connected with other structures. The constraints excited by other connected structures may affect the stiffness of the floor [30]. Thus, the boundary conditions are assumed as follows: (1) the boundary conditions between the floor slab and the frame beams are fixed support, i.e., FEM I and (2) the boundary conditions between the floor slab and the frame beams are simple support, i.e., FEM II.

2.4.2. Pedestrian-Induced Acceleration. The mode is described in Section 2.4.1.

The dynamic responses of jumping excitation refer to the summarized time-history curves proposed by Liu et al. [31] (Figure 7.). $a$ is the jump dynamic factor, $b$ is the duration of feet on the ground, and $T$ is the jumping period. Based on the measured data, when the jumping frequency $f \geq 2.4 \mathrm{~Hz}$, then $a=4.0$ and $b=0.45$; when the jumping frequency $f \leq 2.0 \mathrm{~Hz}$, then $a=3.0$ and $b=0.55$. The jumping excitation is placed in the center of the shaded grid in Figure 6, and the excitation time lasts $40 \mathrm{~s}$.

\section{Results and Discussion}

3.1. Model Test Results. The environmental random vibration stimulating method was used in the experimental test, and the DHC modal analysis system was used to analyze the acquired data. The first four orders of natural frequencies and the damping ratio were obtained, and the results are presented in Table 3. Figure 8 displays the first four orders of the modal shapes.

3.2. Peak Value of Pedestrian-Induced Acceleration. The project is an open public space where visitors can sometimes be relatively concentrated. The last five test conditions are closer to the actual conditions in the building. In this section, the eight test conditions in Section 2.3 are presented.

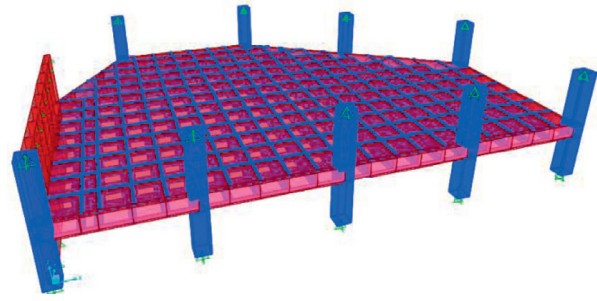

FIGURE 6: FEM of the composite floor.

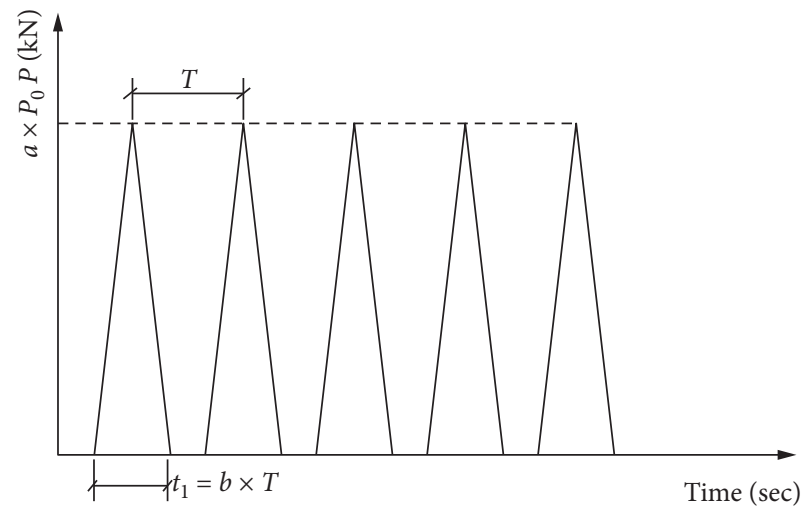

Figure 7: Simplified time history curve of jump excitation.

TABLE 3: Measured modal data of composite floor.

\begin{tabular}{lcccc}
\hline & Order 1 & Order 2 & Order 3 & Order 4 \\
\hline Natural frequency (Hz) & 5.96 & 8.62 & 12.22 & 15.15 \\
Damping ratio (\%) & 4.24 & 2.09 & 4.47 & 0.68 \\
\hline
\end{tabular}

Figure 9 shows these experimental test scenes. The experimenter stood at the point 8 during solo experimenter stepping and jumping. The designated route is along the span direction at the midpoint of the long side of the floor during solo experimenter walking, 10 experimenters in a line walking, and 10 experimenters in a row walking. 12 experimenters stood at the center of each grid $(+)$ in the shadow of Figure 5 during 12 experimenters stepping and jumping. The designed area is the shadow in Figure 5 during 12 experimenters walking.

Table 4 lists the peak accelerations of the measured points under the eight test conditions: peak acceleration at each measured point during solo experimenter stepping $\left(\mathrm{mm} / \mathrm{s}^{2}\right)$; peak acceleration at each measured point during solo experimenter jumping $\left(\mathrm{mm} / \mathrm{s}^{2}\right)$; peak acceleration during solo experimenter walking along a designated route $\left(\mathrm{mm} / \mathrm{s}^{2}\right)$; peak acceleration 10 experimenters in a line walking along a designated route $\left(\mathrm{mm} / \mathrm{s}^{2}\right)$; peak acceleration 10 experimenters in a row walking along a designated route $\left(\mathrm{mm} / \mathrm{s}^{2}\right)$; peak acceleration at each measured point during 12 experimenters stepping $\left(\mathrm{mm} / \mathrm{s}^{2}\right)$; peak acceleration at each measured point during 12 experimenters jumping $\left(\mathrm{mm} / \mathrm{s}^{2}\right)$; peak acceleration 12 experimenters walking in a designated area $\left(\mathrm{mm} / \mathrm{s}^{2}\right)$.

The following points can be observed from Table 4: (1) the peak accelerations increases with the increase of the 


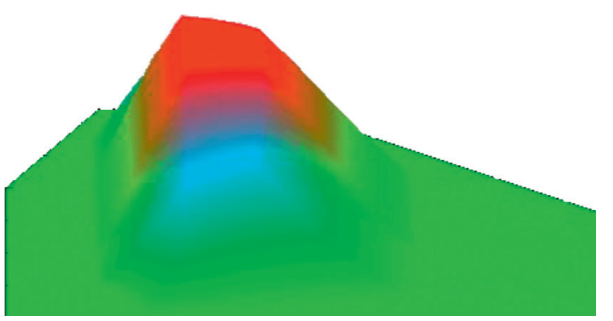

(a)

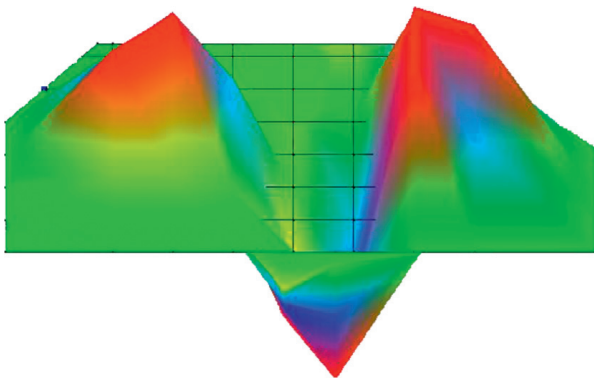

(c)

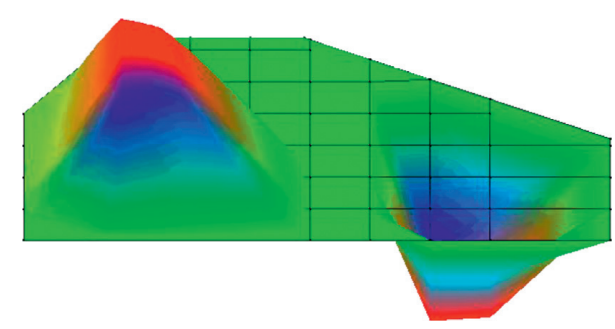

(b)

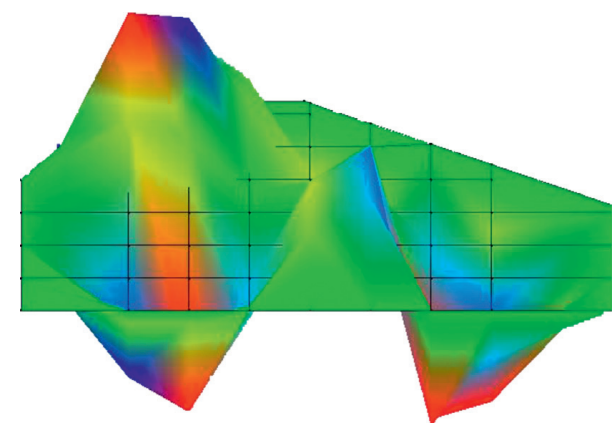

(d)

Figure 8: Measured mode shape of composite floor: (a) order 1; (b) order 2; (c) order 3; (d) order 4.

active frequency at the same measured point under the eight test conditions. (2) Under the eight test conditions, the peak accelerations appears at the measured point 15 which is almost located in the center of the floor. (3) The peak acceleration under solo experimenter jumping is larger than that under solo experimenter stepping at the same active frequency, because the impact force of the jumping on the floor increases larger. (4) 10 experimenters in a line are more disadvantageous than $10 \mathrm{ex}-$ perimenters in a row walking along the span direction at the midpoint of the long side of the floor. (5) The experimental results of 12 experimenters stepping and jumping are similar to (3), the peak acceleration is not big when 12 experimenters walking in the designated area, and the peak acceleration of the floor can meet the specification when many people walk freely. (6) The biggest peak acceleration of measured point 15 is $0.028 \mathrm{~m} /$ $\mathrm{s}^{2}$ under 12 experimenters jumping. The measured results of the peak acceleration meet the requirement of less than $0.05 \mathrm{~m} / \mathrm{s}^{2}$. Also, the measured points near the centroid of the floor possess the larger peak accelerations at the same jumping frequency.

The acceleration time-history curve of measured point 15 under the test conditions of a jumping frequency of $2.4 \mathrm{~Hz}$ with 12 experimenters is shown in Figure 10.

3.3. Modal Analyses Results of FEM. The dynamic structural analysis is based on the dynamic response and the mass equation of the concentrated node. It is important to define the node quality in the FEM analysis. The test floor was undecorated and the node quality was defined as one times the load. As listed in Table 5, because of the influence of the boundary conditions, the natural frequency of FEM I is higher than that of FEM II.
Figure 11 shows the first six mode shapes obtained by the FEM I analyses.

3.3.1. Comparison of Results: Experimental Test and FEM Analyses. The comparison between the experimental tests and FEM analyses under the fixed support boundary condition reveals the following incomplete corresponding relations of the mode shapes. The first two mode shapes of the FEM analyses correspond to the first two mode shapes of the experimental tests. The fourth mode shape of the FEM analyses corresponds to the third mode shape of the experimental test. The sixth mode shape of the FEM analyses corresponds to the fourth mode shape of the experimental test. These results reflect the complexity of the test environment and indicate some mode shapes cannot be excited. Moreover, some signal strengths are too weak to be acquired.

As shown in Table 6, the deviations between FEM I and the experimental tests are less than 5\%. The deviations between FEM II and the experimental tests are larger; the maximum error is $-33.14 \%$, and the minimum error is $-18.1 \%$. The results show that the boundary condition of FEM I is in accordance with the actual condition. The tested floor is connected with adjacent structures which constrain the rotation of the floor, so the boundary condition approximates the fixed support. Thus, the restraint effect of adjacent structures excitation cannot be ignored in the FEM analysis.

Through the comparison between the experimental test mode shapes and FEM I, it is found that the results of FEM I are basically in agreement with the ideal situation, and the center of the experimental mode is slightly shifted to the left because of constraining forces from the connected structures which are the left crossed shear keys and the thicker $\mathrm{U}$-shaped steel. The mode shape curves of the experimental 


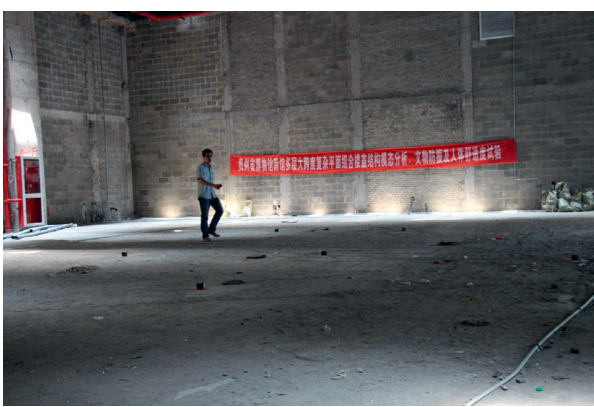

(a)

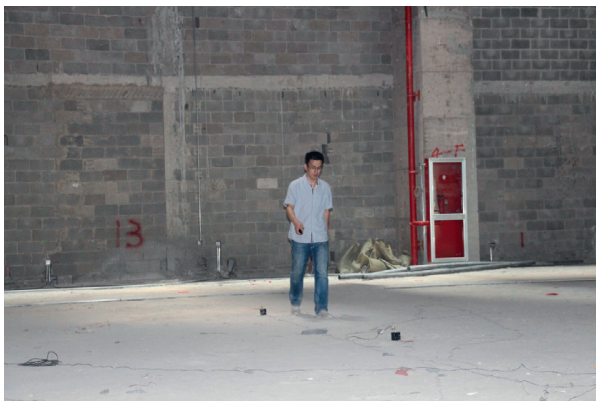

(c)

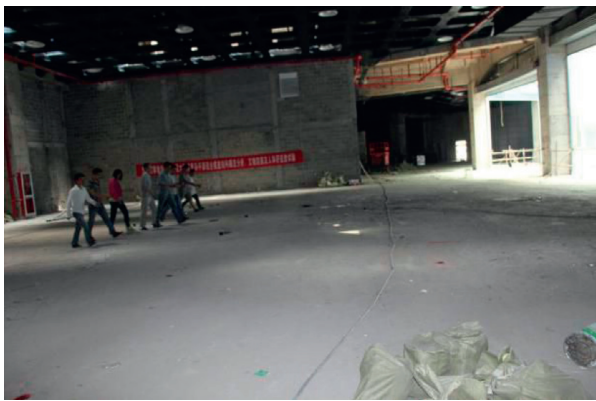

(e)

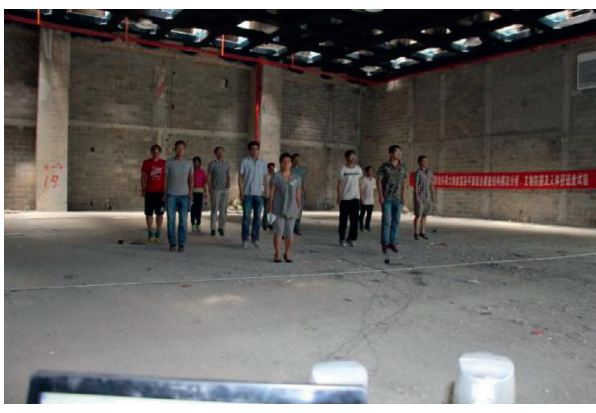

(g)

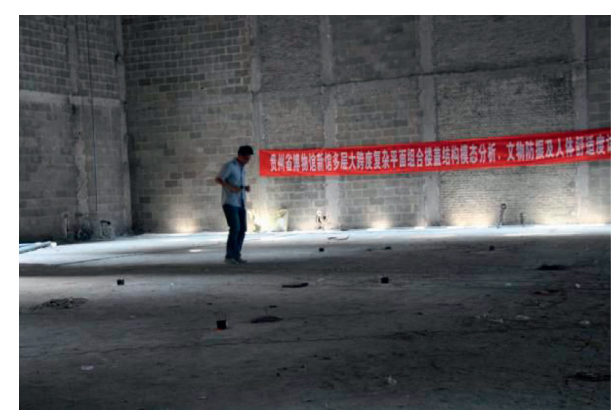

(b)

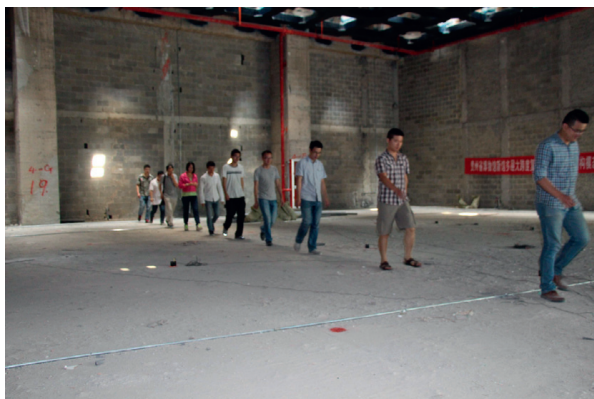

(d)

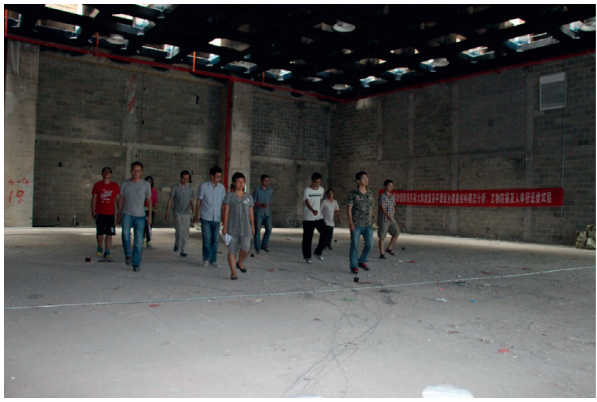

(f)

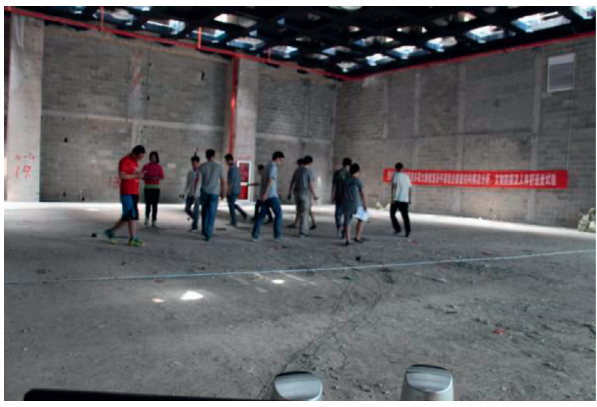

(h)

FIGURE 9: Experimental test: (a) solo experimenter stepping; (b) solo experimenter jumping; (c) solo experimenter walking along a designated route; (d) 10 experimenters in a line walking along a designated route; (e) 10 experimenters in a row walking along a designated route; (f) 12 experimenters stepping; (g) 12 experimenters jumping; (h) 12 experimenters walking in a designated area.

test are smooth, and the mode shapes curves of FEM I have edges. This difference is due to the boundary conditions. The boundary condition in the FEM I is fixed support, which the actual condition cannot meet.

The natural frequency of the experimental test $(5.96 \mathrm{~Hz})$ or the FEM I $(6.18 \mathrm{~Hz})$ exceeds the specification requirement of $3 \mathrm{~Hz}$. The results show that the U-shaped steel-concrete composite floor is suitable for long-span floors and meets the specification requirement of serviceability.

3.3.2. Comparison of Results: Similarity Metric Computation. The similarity between experimental test data and FEM data is estimated by using the modal assurance criterion [32] 
TABLE 4: The peak accelerations of the measured points under the eight test conditions.

\begin{tabular}{|c|c|c|c|c|c|c|c|}
\hline Measuring point & 8 & 9 & 14 & 15 & 16 & 22 & 27 \\
\hline \multicolumn{8}{|l|}{ (a) } \\
\hline $1.7 \mathrm{~Hz}$ & 1.37 & 0.98 & 0.59 & 0.85 & 0.89 & 0.65 & 0.42 \\
\hline $2.1 \mathrm{~Hz}$ & 1.78 & 1.30 & 0.92 & 1.32 & 1.27 & 0.84 & 0.73 \\
\hline $2.4 \mathrm{~Hz}$ & 2.67 & 2.74 & 1.06 & 3.12 & 1.76 & 2.14 & 0.81 \\
\hline \multicolumn{8}{|l|}{ (b) } \\
\hline $1.7 \mathrm{~Hz}$ & 1.44 & 1.02 & 0.78 & 1.12 & 1.15 & 0.81 & 0.53 \\
\hline $2.1 \mathrm{~Hz}$ & 2.39 & 1.57 & 1.96 & 1.44 & 1.42 & 0.91 & 0.78 \\
\hline $2.4 \mathrm{~Hz}$ & 3.41 & 2.82 & 1.21 & 3.73 & 1.96 & 2.25 & 1.26 \\
\hline \multicolumn{8}{|l|}{ (c) } \\
\hline $1.7 \mathrm{~Hz}$ & 1.97 & 1.40 & 0.56 & 0.62 & 1.51 & 1.07 & 0.60 \\
\hline $2.1 \mathrm{~Hz}$ & 3.10 & 3.35 & 0.74 & 0.87 & 2.20 & 2.38 & 1.91 \\
\hline $2.4 \mathrm{~Hz}$ & 4.46 & 4.03 & 5.02 & 6.26 & 5.54 & 4.09 & 2.55 \\
\hline \multicolumn{8}{|l|}{ (d) } \\
\hline $1.7 \mathrm{~Hz}$ & 2.77 & 2.31 & 1.99 & 2.75 & 2.39 & 1.62 & 1.89 \\
\hline $2.1 \mathrm{~Hz}$ & 8.39 & 8.18 & 5.04 & 7.35 & 8.64 & 7.47 & 6.05 \\
\hline $2.4 \mathrm{~Hz}$ & 10.65 & 9.87 & 10.68 & 14.27 & 12.33 & 6.99 & 3.95 \\
\hline \multicolumn{8}{|l|}{ (e) } \\
\hline $1.7 \mathrm{~Hz}$ & 2.34 & 2.22 & 1.77 & 2.44 & 2.24 & 1.10 & 0.63 \\
\hline $2.1 \mathrm{~Hz}$ & 3.11 & 3.44 & 3.17 & 4.39 & 5.09 & 1.41 & 1.02 \\
\hline $2.4 \mathrm{~Hz}$ & 6.80 & 6.47 & 6.74 & 7.49 & 6.48 & 6.34 & 4.97 \\
\hline \multicolumn{8}{|l|}{ (f) } \\
\hline $1.7 \mathrm{~Hz}$ & 12.17 & 13.06 & 12.67 & 12.22 & 12.39 & 11.87 & 11.32 \\
\hline $2.1 \mathrm{~Hz}$ & 13.57 & 13.63 & 13.01 & 14.09 & 14.00 & 12.72 & 11.48 \\
\hline $2.4 \mathrm{~Hz}$ & 17.40 & 20.46 & 18.46 & 22.42 & 21.38 & 20.76 & 13.91 \\
\hline \multicolumn{8}{|l|}{ (g) } \\
\hline $1.7 \mathrm{~Hz}$ & 18.01 & 20.84 & 20.23 & 21.56 & 20.91 & 21.00 & 12.69 \\
\hline $2.1 \mathrm{~Hz}$ & 20.12 & 21.83 & 21.24 & 23.02 & 21.81 & 22.08 & 14.83 \\
\hline $2.4 \mathrm{~Hz}$ & 21.45 & 25.89 & 23.54 & 28.23 & 27.61 & 27.42 & 18.66 \\
\hline \multicolumn{8}{|l|}{ (h) } \\
\hline $1.7 \mathrm{~Hz}$ & 1.61 & 1.23 & 0.82 & 1.45 & 1.24 & 1.06 & 0.75 \\
\hline $2.1 \mathrm{~Hz}$ & 2.67 & 2.76 & 2.72 & 3.35 & 3.44 & 3.28 & 2.39 \\
\hline $2.4 \mathrm{~Hz}$ & 6.95 & 6.02 & 7.06 & 9.64 & 7.78 & 7.64 & 5.19 \\
\hline
\end{tabular}

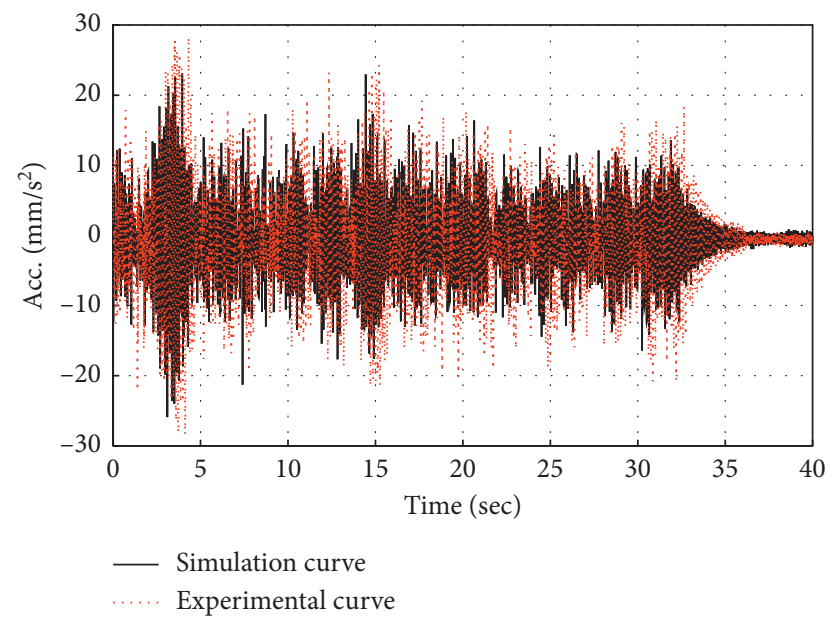

FIgURE 10: Time history of the acceleration response of point 15.

TABLE 5: Calculated frequencies of two types of FEM.

\begin{tabular}{lcccccc}
\hline & Order 1 & Order 2 & Order 3 & Order 4 & Order 5 & Order 6 \\
\hline FEM I & 6.18 & 8.89 & 11.68 & 12.26 & 14.45 & 15.86 \\
FEM II & 4.36 & 7.06 & 7.86 & 9.43 & 9.86 & 10.13 \\
\hline
\end{tabular}




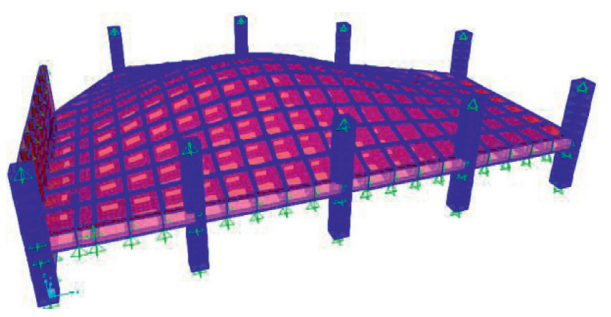

(a)

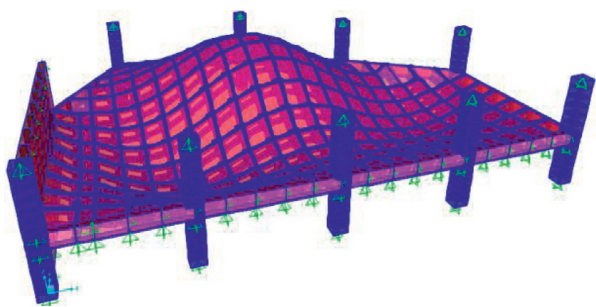

(c)

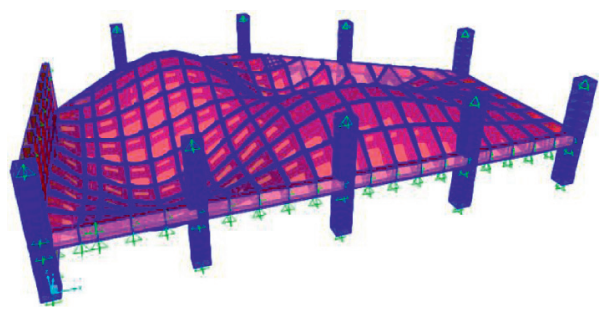

(e)

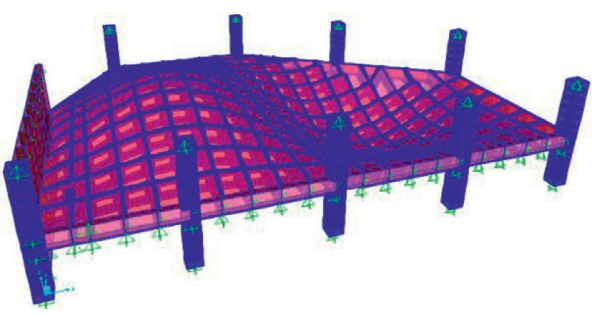

(b)

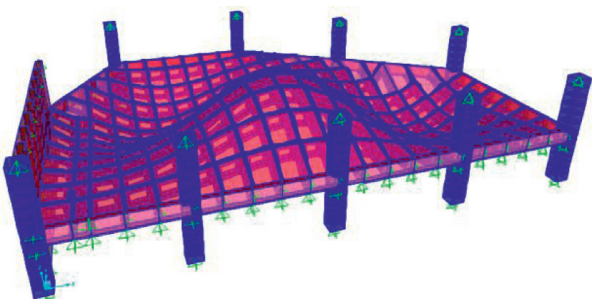

(d)

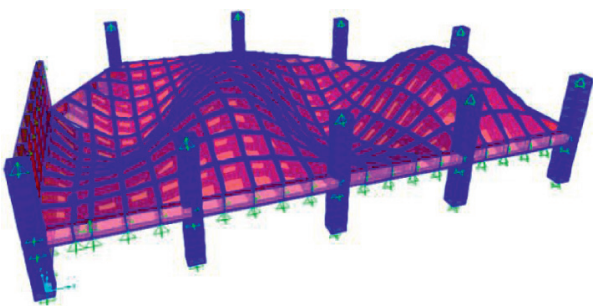

(f)

Figure 11: Mode shapes of FEM I: (a) order 1; (b) order 2; (c) order 3; (d) order 4; (e) order 5; (f) order 6.

TABLE 6: Comparison of FEM and experimental test frequency.

\begin{tabular}{lccccc}
\hline \multirow{2}{*}{ Mode shape } & \multirow{2}{*}{ Field test frequency $(\mathrm{Hz})$} & \multicolumn{2}{c}{ FEM I (fixed) } & \multicolumn{2}{c}{ FEM II (simple) } \\
& & Frequency $(\mathrm{Hz})$ & Relative error (\%) & Frequency (Hz) & Relative error (\%) \\
\hline Order 1 & 5.96 & 6.18 & 3.56 & 4.36 & -26.85 \\
Order 2 & 8.62 & 8.89 & 3.04 & 7.06 & -18.10 \\
Order 3 & & 11.68 & & 9.43 & -22.83 \\
Order 4 & 12.22 & 12.26 & 0.08 & 9.86 & -30 \\
Order 5 & & 14.45 & 4.48 & 10.13 & -33.14 \\
Order 6 & 15.15 & 15.86 & & & \\
\hline
\end{tabular}

(MAC). In this section, MAC is used to verify the experimental test results.

$\phi_{a}$ is the mode vector of the experimental test and $\phi_{b}$ is the corresponding mode vector of FEM I or FEM II. The similarity can be calculated as

$$
\operatorname{MAC}\left(\phi_{a}, \phi_{b}\right)=\frac{\left(\phi_{a}^{T} \phi_{b}\right)^{2}}{\left(\phi_{a}^{T} \phi_{a}\right)\left(\phi_{b}^{T} \phi_{b}\right)}
$$

If the two mode shapes are similar, the MAC value is 1.

There are 38 measuring points in this experimental test; the first fourth order mode vectors of each measured points are extracted. In addition, the first, second, fourth, and sixth order mode vectors of FEM I or FEM II are selected. After extraction, the data are normalized. The MAC values of the experimental test and FEM I or FEM II are calculated by (5). The results are shown in Table 7 . The
TABle 7: Mode shape similarity between FEM and field test.

\begin{tabular}{lcccc}
\hline & Order 1 & Order 2 & Order 3 & Order 4 \\
\hline FEM I and tests & 0.824 & 0.793 & 0.872 & 0.841 \\
FEM II and tests & 0.751 & 0.712 & 0.773 & 0.681 \\
\hline
\end{tabular}

similarity between the experimental test and FEM I is almost all over 0.8 . On the whole, the experimental test results are reliable. The similarity between FEM I and the experimental test is better than that between FEM IIand the experimental test.

3.4. Comparison of Results between Experimental Test and FEM. In this section, the acceleration time-history curves of three measured points (No. 9, No. 15, and No. 27) are compared with that of FEM during 12 experimenters jumping under a frequency $2.4 \mathrm{~Hz}$. These results are 


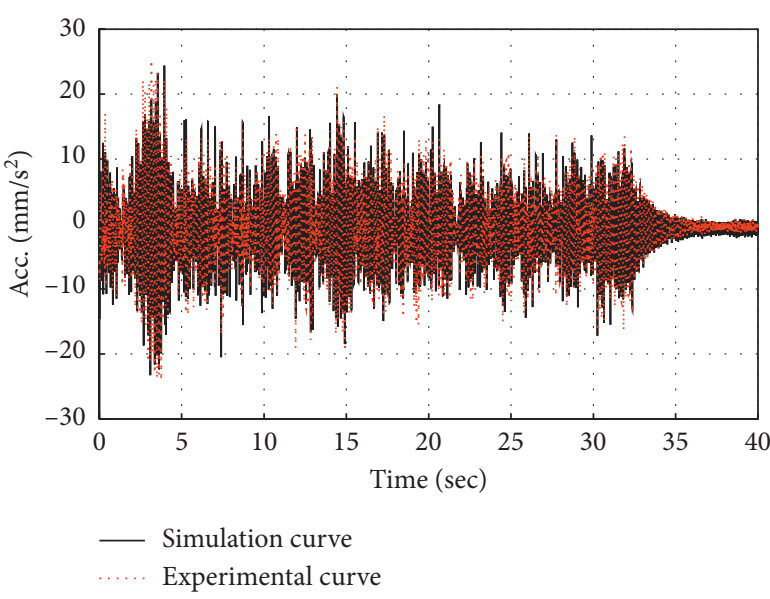

(a)

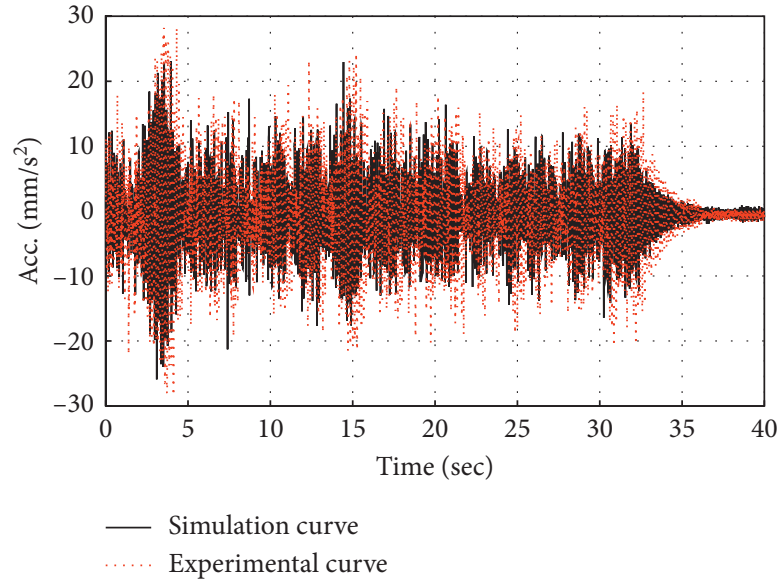

(b)

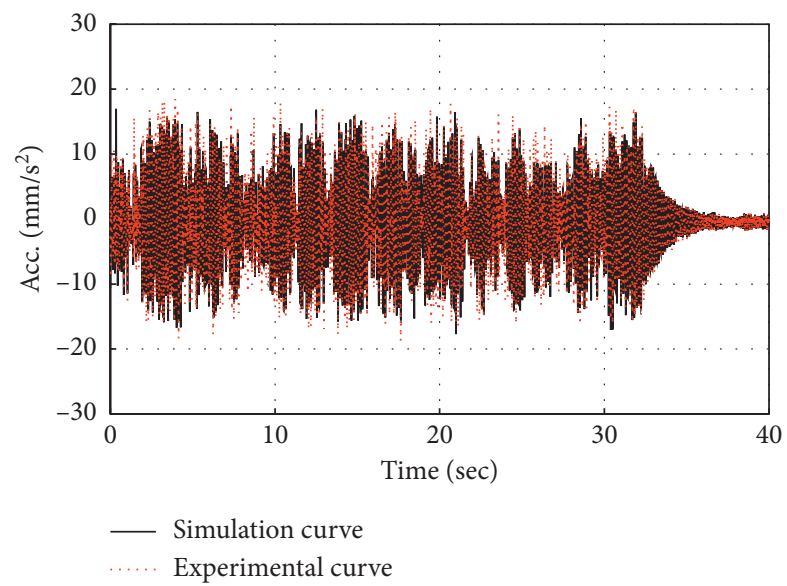

(c)

FIgURE 12: Time-histories of the acceleration response: (a) point 9; (b) point 15; (c) point 27.

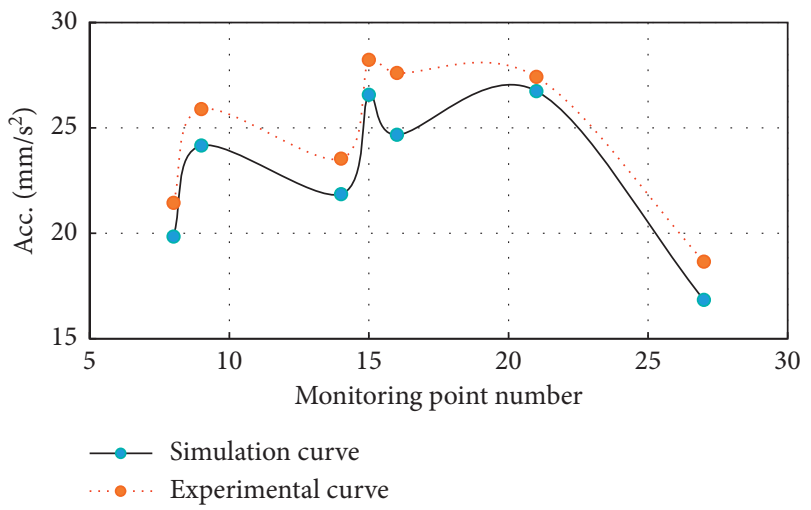

Figure 13: Peak acceleration at each measured point.

plotted in Figure 12. The results indicate that the acceleration time-history curves agree well with the experimental test curves.

Figure 13 compares the peak accelerations between the experimental test data and the FEM data. The results show that the experimental results are higher than those of FEM. This may be due to the fact that the FEM model only the floor tested where the experimental test floor model is connected to other rooms and partitions in some places.

\section{Conclusions}

In this paper, the dynamic responses of the U-shaped steelconcrete composite floor are studied by the method of 
experimental tests and FEM analyses in the MNG project. Based on the results obtained from this investigation, the following significant conclusions are drawn:

(1) The natural frequencies obtained by the experimental test and FEM Ianalyses are $5.96 \mathrm{~Hz}$ and $6.18 \mathrm{~Hz}$, respectively. The results meet the specification requirement of $3 \mathrm{~Hz}$. Thus, the $\mathrm{U}$-shaped steel-concrete composite floor can be used in longspan floors and the natural frequency can meet the specification requirement.

(2) In the FEM modal analyses, the natural frequency of the FEM Ianalyses is similar to that of the experimental test when the boundary conditions of the floor slabs and the frame beams are fixed supports, the natural frequency deviation of the FEM II analyses and the experimental test is larger when the boundary conditions are simple supports. Thus, the restraint effect of adjacent structures excitation cannot be ignored in FEM analyses.

(3) The MAC is applied to estimate the similarity between the experimental test data and the FEM data. The vectors extracted are the first four orders' mode vectors of the experimental test and the first-, second-, fourth-, and sixth-order mode vectors of FEM I and FEMII. The MAC values of the experimental test and FEM I are almost all over 0.8 , and the experimental test results are reliable. The similarity between FEM I and the experimental test is better than that between FEMII and the experimental test.

(4) The peak accelerations are measured under eight test conditions. The peak accelerations increases with the increase of the active frequency at the same measured point because the impact force on the floor increases largely and the peak accelerations is almost located in the center of the floor. The biggest peak acceleration is $0.028 \mathrm{~m} / \mathrm{s}^{2}$ under 12 experimenters jumping which can meet the specification requirement of less than $0.05 \mathrm{~m} / \mathrm{s}^{2}$.

\section{Data Availability}

The data used to support the findings of this study are available from the corresponding author upon request.

\section{Conflicts of Interest}

The authors declare that they have no conflicts of interest.

\section{Acknowledgments}

This research was supported by the Natural Science Foundation of Guizhou Province (project no. [2018]1038), the Natural Science Foundation of Department of Education of Guizhou Province (project no. [2015]430), and the Introduction of Talents Research Program of Guizhou University (project no. [2016]16).

\section{References}

[1] H. Y. Huang, W. S. Chang, and K. M. Mosalam, "Feasibility of shape memory alloy in a tuneable mass damper to reduce excessive in-service vibration," Structural Control and Health Monitoring, vol. 24, no. 2, pp. 18-58, 2017.

[2] B. Ellingwood and A. Tallin, "Structural serviceability: floor vibrations," Journal of Structural Engineering, vol. 110, no. 2, pp. 401-418, 1984.

[3] P. Aleksandar, R. Paul, W. Peter et al., "Dynamic modelling of post-tensioned concrete floors using finite element analysis," Finite Elements in Analysis and Design, vol. 37, no. 4, pp. 305-323, 2001.

[4] G. S. A Silva Jose, A. L. De Andrade Sebastiao, and D. C. Lopes Elvis, "Parametric modelling of the dynamic behavior of a steel-concrete composite floor," Engineering Structures, vol. 75, pp. 327-339, 2014.

[5] A. V. A. Mello, J. G. S. Da Silva, P. C. G. D. S. Vellasco, S. A. L. De Andrade, and L. R. O. De Lima, "Dynamic analysis of composite systems made of concrete slabs and steel beams," Journal of Constructional Steel Research, vol. 64, no. 10, pp. 1142-1151, 2008.

[6] Q. H. Han, Y. H. Wang, J. Xu et al., "Nonlinear numerical analysis of elastic concrete-steel composite beams," Journal of Tianjin University, vol. 47, pp. 91-95, 2014.

[7] W. D. Varela and R. C. Battista, "Control of vibrations induced by people walking on large span composite floor decks," Engineering Structures, vol. 33, no. 9, pp. 2485-2494, 2011.

[8] S. S. De Silva and D. P. Thambiratnam, "Dynamic characteristics of steel-deck composite floors under human-induced loads," Computers and Structures, vol. 87, no. 17, pp. 10671076, 2009.

[9] J. G. S. Da Silva, P. C. G. D. S. Vellasco, S. A. L. De Andrade, F. J. D. C. P. Soeiro, and R. N. Werneck, "An evaluation of the dynamical performance of composite slabs," Computers \& Structures, vol. 81, no. 18-19, pp. 1905-1913, 2003.

[10] E. El-Dardiry and T. Ji, "Modelling of the dynamic behavior of profiled composite floors," Engineering Structures, vol. 28, no. 4, pp. 567-579, 2005.

[11] J. J. Liu, K. J. Ma, Y. H. Wei et al., "Comfort degree analysis and field measurement of single-span multistoried large-span steel grid cassette structural composite open web floors," Building Structure, vol. 46, no. 16, pp. 79-82, 2016.

[12] L. Jiang, K. J. Ma, H. G. Zhang et al., "The dynamic property and comfort degree study on the steel-concrete composite vierendeel sandwich plate," Earthquake Engineering and Engineering Dynamics, vol. 37, no. 6, pp. 122-131, 2017.

[13] R. M. Lawson, J. Lim, S. J. Hicks, and W. I. Simms, "Design of composite asymmetric cellular beams and beams with large web openings," Journal of Constructional Steel Research, vol. 62, no. 6, pp. 614-629, 2006.

[14] S. Hicks, "Current trend in modern floor construction," British Constructional Steelwork Association, vol. 11, no. 1, pp. 32-33, 2003.

[15] S. Ivanovic, A. Pavic, and P. Reynolds, "Vibration comfortableness of footbridges under human-induced excitation: a literature review," Journal of Sound and Vibration, vol. 279, pp. 1-74, 2005.

[16] V. Racic, A. Pavic, and J. M. W. Brownjohn, "Experimental identification and analytical modelling of human walking forces: literature review," Journal of Sound and Vibration, vol. 326, no. 1-2, pp. 1-49, 2009. 
[17] S. Yao, J. R. Wright, A. Pavic, and P. Reynolds, "Experimental study of human-induced dynamic forces due to jumping on a perceptibly moving structure," Journal of Sound and Vibration, vol. 296, no. 1-2, pp. 150-165, 2006.

[18] S. C. Kerr and N. W. M. Bishop, "Human induced loading on flexible staircases," Engineering Structures, vol. 23, no. 1, pp. 37-45, 2001.

[19] V. Racic and A. Pavic, "Mathematical model to generate nearperiodic human jumping force signals," Mechanical Systems and Signal Processing, vol. 24, no. 1, pp. 138-152, 2010.

[20] V. Racic, J. M. W. Brownjohn, and A. Pavic, "Reproduction and application of human bouncing and jumping forces from visual marker data," Journal of Sound and Vibration, vol. 329, no. 16 , pp. 3397-3416, 2010.

[21] V. Racic and A. Pavic, "Stochastic approach to modelling of near-periodic jumping loads," Mechanical Systems and Signal Processing, vol. 24, no. 8, pp. 3037-3059, 2010.

[22] V. Racic and J. M. W. Brownjohn, "Stochastic model of nearperiodic vertical loads due to humans walking," Advanced Engineering Informatics, vol. 25, no. 2, pp. 259-275, 2011.

[23] S.-I. Nakamura, T. Kawasaki, H. Katsuura, and K. Yokoyama, "Experimental studies on lateral forces induced by pedestrians," Journal of Constructional Steel Research, vol. 64, no. 2, pp. 247-252, 2008.

[24] China Construction Industry Press, Concrete Structure Design Specification: GB 50010-2010, China Construction Industry Press, Beijing, China, 2010.

[25] China Construction Industry Press, Technical Regulations on Concrete Structure in High-Rise Buildings: JGJ 3-2010, China Construction Industry Press, Beijing, China, 2010.

[26] China Planning Press, Code of Design and Construction of Composite Buildings: CECS 273, China Planning Press, Beijing, China, 2010.

[27] G. De Rocek, "Benchmark study on system identification through ambient vibration measurements," in Proceedings of the 18th IMAC, pp. 1106-1112, San Antonio, TX, USA, February 2000.

[28] M. Petyt and W. H. Mirza, "Vibration of column-supported floor slabs," Journal of Sound and Vibration, vol. 21, no. 3, pp. 355-364, 1972.

[29] P. Aleksandar and R. Paul, "Vibration comfortableness of long-span concrete building floors," The Shock and Vibration Digest, vol. 34, no. 7, pp. 191-211, 2002.

[30] X. Zhou, J. Liu, L. Cao, and J. Li, "Vibration serviceability of pre-stressed concrete floor system under human activity," Structure and Infrastructure Engineering, vol. 13, no. 8, pp. 967-977, 2017.

[31] J. Liu, C. Xiao, C. Pan et al., "Investigation on response of floor vibration under jumping and walking excitation," Building Structure, vol. 38, no. 11, pp. 108-110, 2008.

[32] R. J. Allemang and D. L. A. Brown, "Correlation coefficient for modal vector analysis," in Proceedings of the 1st IMAC, pp. 110-116, Orlando, FL, USA, 1982. 